\title{
Drug dosing in the critically ill obese patient: a focus on medications for hemodynamic support and prophylaxis
}

\author{
Brian L. Erstad ${ }^{1}$ and Jeffrey F. Barletta ${ }^{2^{*}}$ (])
}

\begin{abstract}
Medications used for supportive care or prophylaxis constitute a significant portion of drug utilization in the intensive care unit. Evidence-based guidelines are available for many aspects of supportive care but drug doses listed are typically for patients with normal body habitus and not morbid obesity. Failure to account for the pharmacokinetic changes that occur with obesity can lead to an incorrect dose and treatment failure or toxicity. This paper is intended to help clinicians design initial dosing regimens in critically ill obese patients for medications commonly used for hemodynamic support or prophylaxis. A detailed literature search of medications used for supportive care or prophylaxis listed in practice guidelines was conducted with an emphasis on obesity, pharmacokinetics and dosing. Relevant manuscripts were reviewed and strategies for dosing are provided. For medications used for hemodynamic support, a similar strategy can be used as in non-obese patients. Similarly, medications for stress ulcer prophylaxis do not need to be adjusted. Anticoagulants for venous thromboembolism prophylaxis, on the other hand, require an individualized approach where higher doses are necessary.
\end{abstract}

Keywords: Critical illness, Obesity, Pharmacokinetics, Drug dosing

\section{Introduction}

Medications for supportive care and prophylaxis constitute a large proportion of drug use in the intensive care unit (ICU). In fact, evidence-based guidelines exist for many of the therapies considered "routine care" and form the basis for checklists and standardization of therapy. The drug doses that are included, however, are often formulated for patients with normal body habitus and do not account for the pharmacokinetic variability encountered with obesity. This is concerning because clinical trials that provide efficacy and safety data for the ICU rarely include obese individuals thereby presenting a unique challenge for bedside clinicians when designing a dosing

*Correspondence: jbarle@midwestern.edu

2 Department of Pharmacy Practice, College of Pharmacy, Midwestern University, 19555 N 59th Ave, Glendale, AZ 85308, USA

Full list of author information is available at the end of the article regimen. Most data in this area are from studies that utilize pharmacokinetic variables, surrogate markers for efficacy or physicochemical characteristics. Nevertheless, clinicians must still make important dosing decisions at the bedside despite the limited amount of data that are available.

Recent data from the CDC indicate the prevalence of obesity (BMI $\left.\geq 30 \mathrm{~kg} / \mathrm{m}^{2}\right)$ among US adults is $42.4 \%$ [1]. Furthermore, there is an alarming increase in the prevalence of severe obesity $\left(B M I \geq 40 \mathrm{~kg} / \mathrm{m}^{2}\right)$ which has risen from $4.7 \%$ in 1999 to $9.2 \%$ in 2018 . Unfortunately, this trend has not been recognized with regard to the availability of obesity-specific dosing information in product labeling. One study, published in 2020, stated only $30 \%$ of medications evaluated had some reference to a weight descriptor in the dosing information compared to $27 \%$ reported in a similar study conducted about 10 years prior $[2,3]$. This is problematic because the use of an original author(s) and the source, provide a link to the Creative Commons licence, and indicate if changes were made. The images or other third party material in this article are included in the article's Creative Commons licence, unless indicated otherwise in a credit line to the material. If material is not included in the article's Creative Commons licence and your intended use is not permitted by statutory regulation or exceeds the permitted use, you will need to obtain permission directly from the copyright holder. To view a copy of this licence, visit http://creativecommons.org/licenses/by/4.0/. The Creative Commons Public Domain Dedication waiver (http://creativeco mmons.org/publicdomain/zero/1.0/) applies to the data made available in this article, unless otherwise stated in a credit line to the data. 
incorrect weight metric, for weight-based dosing, could lead to treatment failure (in the event of subtherapeutic levels) or drug toxicity (caused by supratherapeutic levels) (Fig. 1). Knowledge of the most appropriate weightmetric for each medication is essential to optimize outcomes with drug therapy in the critically ill obese patient.

The weight metric used to characterize weight status is body mass index (BMI). Body mass index, however, is not commonly used for drug dosing. The weight metrics most commonly referenced when dosing medications in the ICU are total body weight or some alternative, such as ideal body weight (IBW), lean body weight (LBW) or adjusted body weight (Table 1). Ideal body weight characterizes weight based on height and gender. It was formulated more than 60 years ago using actuarial data based on the premise that for a given height, there was an ideal weight [4]. Ideal body weight does not account for differences in body composition or the increases in absolute lean mass that typically accompany obesity. Thus, it is inherently flawed as a surrogate for fat-free mass. Lean body weight appears to be the best representation of fatfree mass [5]. These equations, however, are prone to calculation errors so software programs are recommended. Adjusted body weight using a correction factor (i.e., a fraction of the difference between total and ideal body weight) is commonly used for drug dosing, and these equations are well known by most practitioners. Adjusted body weight is roughly equivalent to LBW and for the purposes of this paper will be considered a surrogate (for LBW) because of familiarity and ease of calculation.

Designing dosing regimens in the critically ill obese patient requires a detailed understanding of the physicochemistry of the medication, and the impact obesity has (coupled with critical illness) on physiology and drug pharmacokinetics [6]. Because of the tremendous variability observed, an individualized dosing approach is preferred [7]. Generalized clinical pearls exist to assist with dosing in this challenging population (Table 2) but specific dosing recommendations to guide clinicians are

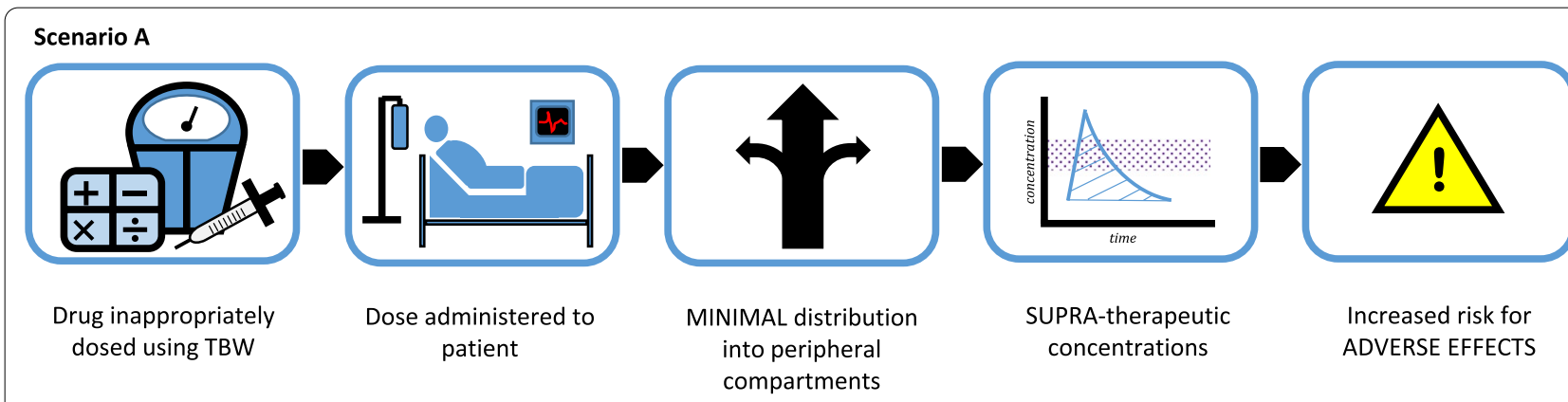

Scenario B

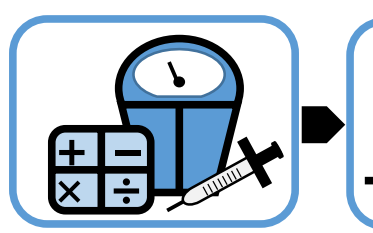

Drug inappropriately dosed using IBW

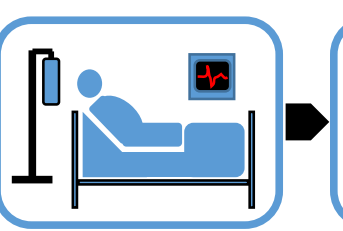

Dose administered to patient

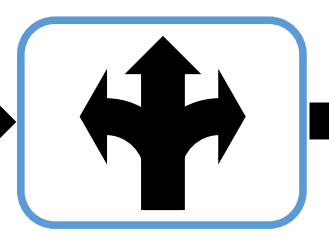

EXTENSIVE distribution into peripheral compartments

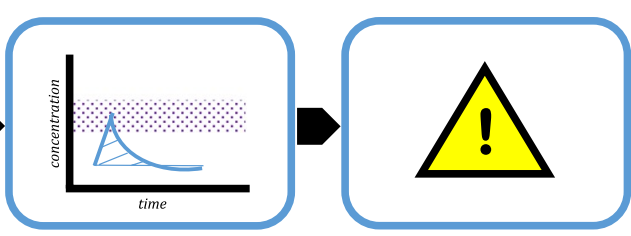

SUB-therapeutic concentrations
Increased risk for TREATMENT FAILURE

Fig. 1 Consequences of using an incorrect weight metric when dosing weight-based medications in obese patients

Table 1 Common weight measures used to estimate size when dosing medications in obese patients

\begin{tabular}{ll}
\hline Weight measure & Equation \\
\hline Body mass index $\left(\mathrm{kg} / \mathrm{m}^{2}\right)$ & TBW/height $(\mathrm{m})^{2}$ \\
Ideal body weight $(\mathrm{kg})[74]$ & Males: $50 \mathrm{~kg}+2.3 \mathrm{~kg} /$ inch for height over 5 feet \\
& Females: $45.5 \mathrm{~kg}+2.3 \mathrm{~kg} / \mathrm{inch}$ for height over 5 feet \\
Lean body weight $(\mathrm{kg})[5]$ & Males: $(9270 \times \mathrm{TBW}) /(6680+216 \times \mathrm{BMI})$ \\
& Females: $(9270 \times \mathrm{TBW}) /(8780+244 \times$ BMI) \\
Adjusted body weight $(\mathrm{kg})[75]$ & $\mathrm{CF}(\mathrm{TBW}-\mathrm{IBW})+\mathrm{IBW}$, where CF $=$ correction factor (usually 0.4)
\end{tabular}


Table 2 Generalized clinical pearls for crafting medication doses in the setting of extreme obesity

- Seek consistency within and between all healthcare professionals involved in size estimates

- Clearly document instrument (e.g., type of scale) and methods used (e.g., clothes on or off) for weight measurement

- Document when estimates or patient-stated weights are utilized

-When using total body weight, do not change the weight used for calculations (due to weight gain or loss) after therapy has been initiated

- Clinical monitoring of the individual patient's response to therapy should supersede data from pharmacokinetic studies

- Pharmacokinetic parameters (volume of distribution, clearance) are typically greater and with more variability in critically ill versus non-critically ill patients

- Assess for dose-proportionality using pharmacokinetic studies that report volume of distribution and clearance in obese and non-obese individuals

- The duration of action of a single dose (i.e., a loading dose) is generally a function of volume of distribution rather than clearance

- Always assess the benefits and risks of the dosing regimen especially when using a larger dose or total body weight for calculations (i.e., is there a narrow therapeutic index or dose-related adverse effects)

- Use technology or automated dosing calculators to minimize calculation errors

- Even with medications that can be rapidly titrated to effect, using an inappropriate weight metric for weight-based dosing can lead to adverse effects upon initiation or maximum doses above-recommended values

limited. The purpose of this paper is to assist clinicians with dosing regimens for medications commonly used as part of the supportive care and prophylaxis in critically ill obese patients.

\section{Methodology}

The medications reviewed for evaluation consisted of those used for supportive care or prophylaxis mentioned in evidence-based guidelines. Published guidelines from the following therapeutic domains were screened: pain, agitation, delirium, neuromuscular blockade, hemodynamic support in sepsis, stress ulcer prophylaxis and venous thromboembolism prophylaxis [8-12]. Antimicrobials were not included given the overarching theme of this manuscript coupled with the availability of other manuscripts providing dosing recommendations in this area [13-15]. Furthermore, thorough reviews providing recommendations for medications used for pain, agitation, delirium and neuromuscular blockade are also available and the reader is referred to these texts $[16,17]$. Thus, the remaining areas included were medications for hemodynamic support in shock (i.e., vasopressors and corticosteroids), stress ulcer prophylaxis and venous thromboembolism.

A detailed literature search was performed using PubMed from inception to July 2020, using search terms from the following three categories: (1) obesity: "Obesity"[Mesh] OR "Overweight"[Mesh] OR "body composition"[MeSH Terms] OR "extreme obesity" OR "body weight change*" OR "body size" OR "body fat" OR "body fatness" (2) pharmacokinetics and dosing: "Drug Monitoring"[Mesh] OR "Dose-Response Relationship, Drug"[Mesh] OR "pharmacokinetic" OR "pharmacokinetic considerations " OR "drug dosing" OR "drug dose" OR "therapeutic drug monitoring" OR "drug monitoring" and (3) the specific drug in question. The results from the primary literature search were reviewed and pertinent articles were retained. Bibliographies were reviewed for any articles that may have been missed by the primary literature search. Non-English articles and animal studies were not included. The focus will be on adult patients with more severe forms of obesity (i.e., BMI $\geq 40 \mathrm{~kg} / \mathrm{m}^{2}$ ), since such patients are typically limited in numbers in the studies used to formulate product labeling information. A comprehensive, online database was consulted for drug physicochemical properties (e.g., octanol-water partition coefficient $(\log P)$ ) [18]. This database provides detailed drug data (e.g., chemical, pharmacological and pharmaceutical) and comprehensive drug target information (e.g., sequence, structure and pathway) with more than 14,000 drug entries. Suggestions were then formed using the available data based on the following prioritization strategy: studies evaluating clinical outcomes, pharmacokinetics, adverse effect profiles and physicochemical properties. Because of the heterogeneity of study outcomes (i.e., pharmacokinetic-related, clinical outcome, etc.) and the expected lack of information for many of the medications included, advanced statistical techniques such as meta-analysis were not performed.

\section{Vasopressors}

All of the commonly used vasopressors are hydrophilic as indicated by negative $\log P$ values, so distribution is typically limited at most to the extracellular fluid compartment. Small volumes of distribution combined with rapid clearance values results in short half-lives for these agents typically necessitating their administration as continuous intravenous infusions. Irrespective of obesity, there is substantial variability in the pharmacokinetics and pharmacodynamics of vasoactive agents 
(dopamine, dobutamine, epinephrine, norepinephrine and angiotensin II) when used in critically ill patients [19-23]. These physicochemical, pharmacokinetic and pharmacodynamic characteristics argue for the use of non-weight-based dosing regimens, or for weight-based dosing regimens with the use of an IBW or lean body mass descriptor.

In multicenter, retrospective studies evaluating the outcomes of patients with severe infections including septic shock, obese patients received significantly lower weight-based doses of fluids, norepinephrine and other vasopressors compared to normal-weight patients with either no change or lower overall mortality [24-26]. Further, data from single-center, retrospective evaluations investigating weight descriptors for dosing vasopressor medications in critically ill, obese patients demonstrate substantial inter-patient variability in response to vasopressor administration with no consistent weight-based, dose-response relationship [27-31].

Summary: For vasopressors administered as continuous infusions, either a non-weight-based dosing regimen, or a weight-based dosing regimen using an ideal or adjusted body weight is suggested for initial doses in obese patients. If a weight-based method is chosen, seek consistency between using ideal or adjusted body weight across different vasopressor agents (e.g., norepinephrine and dopamine) to minimize error risk.

\section{Corticosteroids}

The majority of studies published to date evaluating relationships between corticosteroids and obesity concern hypothalamic-pituitary-adrenal axis regulation and cortisol activity [32]. In one of the few pharmacokinetic studies involving corticosteroids and obese subjects, methylprednisolone pharmacokinetics were compared in 6 obese and 6 non-obese males [33]. Obese patients received a dose of $0.6 \mathrm{mg} / \mathrm{kg}$ while non-obese subjects received a fixed dosage of $40 \mathrm{mg}$ (approximately $0.5 \mathrm{mg}$ / $\mathrm{kg}$ based on reported total body weight). Volume of distribution was closely related to IBW suggesting limited distribution into adipose tissue. The authors concluded doses based on IBW and not total body weight were recommended. In a second study prednisolone disposition was assessed in 8 obese and 4 normal-weight (i.e., actual weight equaled IBW) men after a single intravenous injection of $33 \mathrm{mg}$ [34]. The obese compared to the normal-weight subjects had proportional increases in volume of distribution (approximately 20\%) and clearance (approximately 35\%) which were less than the proportional differences in actual body weight in the obese subjects ( $62 \%$ above IBW). The differences in the pharmacokinetic parameters in the obese subjects are more consistent with those expected from hydrophilic medications that primarily distribute into lean tissue, rather than the dose proportional increases expected with more lipophilic agents (e.g., $\log P$ values between 1 and 2) like corticosteroids. Additionally, corticosteroids easily pass through cell membranes to bind to cytosolic glucocorticoid receptors that are present in almost all body cells, so the relationship between pharmacokinetic and pharmacodynamics effects is complex [35]. All of these issues complicate the choice of an appropriate size descriptor when considering weight-based dosing regimens. In adult critically ill patients, current guidelines recommend intravenous doses of hydrocortisone equivalents of less than $400 \mathrm{mg}$ daily for hospitalized patients with community-acquired pneumonia or septic shock unresponsive to fluids and vasopressors, and intravenous doses of methylprednisolone of $1 \mathrm{mg} / \mathrm{kg}$ daily for patients with early moderate to severe acute respiratory distress syndrome (ARDS) $[9,11]$. These doses result in supraphysiological levels of corticosteroid in terms of cortisol equivalents [36].

Summary: For non-weight-based dosing of hydrocortisone in patients with community-acquired pneumonia or septic shock unresponsive to fluids and vasopressors, intravenous doses of hydrocortisone in obese patients should be the same as those used in non-obese patients. For weight-based dosing of methylprednisolone for patients with ARDS, the use of an ideal or adjusted body weight is suggested for weight-based dosing in obese patients, particularly in patients with more severe forms of obesity (e.g., BMI of $40 \mathrm{~kg} / \mathrm{m}^{2}$ or greater).

\section{Stress ulcer prophylaxis}

Acid suppressive therapy is routinely administered to critically ill patients for the prevention of clinically important gastrointestinal bleeding (CIB) due to stress ulcers. The agents most commonly chosen for stress ulcer prophylaxis (SUP) are the proton pump inhibitors (PPI) followed by histamine-2-receptor-antagonists (H2RA) [37]. Unfortunately, clinical trials comparing effectiveness in obese patients are lacking. In the most recent prospective trials evaluating SUP, weight is not reported, making the impact of obesity on outcomes difficult to determine [38-40].

The PPIs and H2RA's are both considered acceptable therapy for the provision of SUP but there are some differences in their pharmacokinetic profiles that could be affected by obesity. Proton pump inhibitors are highly lipophilic as prodrugs, which promote distribution into adipose tissue. The H2RA's, on the other hand, are hydrophilic compounds and poorly distribute into fat. Pantoprazole, lansoprazole, omeprazole and esomeprazole are metabolized through the cytochrome P-450 (CYP) system. (Rabeprazole is metabolized by a non-enzymatic 
process.) Both animal and human studies have shown a correlation between increased liver fat content and decreased CYP activity [41]. This relationship has not been quantified across varying degrees of obesity; thus, the clinical significance remains unknown. Body mass index has been associated with nonalcoholic fatty liver disease in a near-linear relationship [42]. Histamine-2-receptor antagonists are metabolized through non-CYP pathways and primarily eliminated renally [43].

There are limited studies evaluating the pharmacokinetics of acid suppressive medications in obesity and none are specific to ICU patients for the provision of SUP. Most data originate from pharmacokinetic studies conducted in healthy volunteers or symptom-related outcomes in patients with gastroesophageal reflux disease (GERD). Furthermore, few patients in these studies had more extreme forms of obesity (e.g., BMI $>40 \mathrm{~kg} /$ $\mathrm{m}^{2}$ ). Extrapolation of these results to the ICU population can be difficult due to the differences in pathophysiological features (between CIB due to stress ulceration and GERD) and alterations that occur in critical illness. One study evaluated the effect of obesity on intragastric $\mathrm{pH}$ following a single dose of PPI (pantoprazole or rabeprazole) in patients with GERD [44]. There was no correlation between $\mathrm{BMI}$ and the total time with $\mathrm{pH}>4$. Other studies have evaluated outcomes in GERD patients such as esophageal $\mathrm{pH}$, heartburn symptoms and healing of erosive esophagitis [45-47]. Overall, these studies have demonstrated no differences based on BMI. Weightbased dosing of PPI's has been evaluated in the pediatric population. These studies have revealed PPI exposure correlates best with lean body weight dosing as opposed to actual body weight $[48,49]$. Collectively, these data reveal that despite some of the theoretical pharmacokinetic concerns with PPI's in obesity, obesity has minimal impact on PPI-related pharmacodynamics.

Similar to PPI's, the pharmacokinetic parameters of H2RA's are not largely affected by obesity [50-52]. In one study of surgical patients with $\mathrm{BMI} \geq 35 \mathrm{~kg} / \mathrm{m}^{2}$, preoperative ranitidine was effective in increasing gastric $\mathrm{pH}$ $(6.1 \pm 1.2)$ compared to unmedicated controls $(3.5 \pm 1.6)$ [53]. Standard doses of H2RA's therefore seem to be adequate.

Summary: Standard, non-weight-based doses for both H2RA's and PPI's are appropriate for stress ulcer prophylaxis in obese critically ill patients.

\section{Venous thromboembolism prophylaxis}

Obesity is a well-known risk factor for venous thromboembolism (VTE) in both critically ill and non-critically ill patients. In a risk factor analysis using data from a large randomized thromboprophylaxis trial, each 10-point increase in BMI was associated with a significant increase in both proximal deep vein thrombosis [HR (95\% CI) 1.25 (1.06-1.46)] and pulmonary embolism [HR (95\% CI) 1.37 (1.02-1.83)] [54]. Prophylaxis in the ICU is typically provided with low molecular weight heparin or unfractionated heparin using a fixed dosing strategy as recommended by the package insert. Standard dosing strategies, however, may be inadequate as several studies have demonstrated an inverse linear relationship between total body weight and anti-Xa activity $[55,56]$. Unfortunately, the majority of the data are in the bariatric surgery population, so do not necessarily account for the pharmacokinetic variability observed in the critically ill that results from a variety of factors including the use of vasopressors and tissue edema [57, 58]. Furthermore, there are few studies focused on clinical outcomes such as VTE incidence; instead, most endpoints were directed toward surrogate markers (e.g., anti-Xa levels) [59-69]. One retrospective, before-after study compared VTE rates using two enoxaparin dosing regimens $(30 \mathrm{mg}$ or $40 \mathrm{mg}$ subcutaneous twice daily) in a cohort of bariatric surgical patients [67]. Postoperative VTE was significantly lower with the higher dosing regimen $(5.4 \%$ vs. $0.6 \%, p<0.01)$. There was no difference in the incidence of hemorrhage. A second retrospective study evaluated the efficacy and safety of enoxaparin and heparin in patients who weighed at least $100 \mathrm{~kg}$ [69]. In this study, patients were stratified according to receipt of a standard or high dose of anticoagulant $(80 \mathrm{mg} /$ day of enoxaparin or 22,500 units/day of unfractionated heparin). In the cohort of patients with a BMI of at least $40 \mathrm{~kg} / \mathrm{m}^{2}$, the VTE rate was $1.48 \%$ with standard dosing compared to $0.77 \%$ in the high-dose group [OR $(95 \%$ CI) $0.52(0.27-1.00) ; p=0.05]$. Similar to the previous study, no difference in hemorrhage was noted.

In light of the evidence surrounding low molecular weight heparin dosing in obesity, several alternative approaches have been evaluated based on anti-Xa levels. There is wide disparity in the doses of low molecular weight heparin utilized, the patient populations studied and the degree of obesity present among the patients. In one study specific to critically ill patients, 23 surgical ICU patients with a mean BMI of $46.4 \pm 11.7 \mathrm{~kg} / \mathrm{m}^{2}$ and weight of $137 \pm 37 \mathrm{~kg}$ reported anti-Xa levels following a $0.5 \mathrm{mg} / \mathrm{kg}$ twice daily enoxaparin regimen [62]. Initial anti-Xa levels were in the appropriate range $(0.2-0.5 \mathrm{IU} /$ $\mathrm{ml}$ ) in $91 \%$ of patients and none experienced major bleeding. A second retrospective study evaluated weightbased dosing of enoxaparin $(0.5 \mathrm{mg} / \mathrm{kg}$ twice daily) in obese trauma patients [59]. In this study, the median BMI and weight was $35.3 \mathrm{~kg} / \mathrm{m}^{2}$ and $113 \mathrm{~kg}$, respectively. Target anti-Xa levels $(0.2-0.6 \mathrm{IU} / \mathrm{ml})$ were achieved in $86 \%$ of patients and no patients experienced a bleeding event. A third trial randomized hospitalized medical patients 
to receive enoxaparin $40 \mathrm{mg}$ daily, $0.4 \mathrm{mg} / \mathrm{kg}$ daily or $0.5 \mathrm{mg} / \mathrm{kg}$ daily [61]. The average BMI in each of the study cohorts exceeded $60 \mathrm{~kg} / \mathrm{m}^{2}$ while weight was greater than $170 \mathrm{~kg}$ (range 115-256 kg). The primary outcome was achievement of target anti-Xa level $(0.2-0.5 \mathrm{IU} / \mathrm{ml})$, which was reached significantly more often in the $0.5 \mathrm{mg} /$ $\mathrm{kg} /$ day group compared to the other regimens. The incidence of subtherapeutic anti-Xa levels was $87 \%, 36 \%$ and $18 \%$ for the fixed (non-weight-based), $0.4 \mathrm{mg} / \mathrm{kg}$ and $0.5 \mathrm{mg} / \mathrm{kg}$ regimens, respectively. Finally, one prospective trial evaluated a BMI-stratified dosing approach in a cohort of bariatric surgery patients [60]. Patients with a $\mathrm{BMI} \leq 50 \mathrm{~kg} / \mathrm{m}^{2}$ received an enoxaparin dosage of $40 \mathrm{mg}$ twice daily while patients in excess of $50 \mathrm{~kg} / \mathrm{m}^{2}$ received $60 \mathrm{mg}$ twice daily. The average BMI in each of the groups was $44.9 \pm 3.7 \mathrm{~kg} / \mathrm{m}^{2}$ and $57.4 \pm 6.4 \mathrm{~kg} / \mathrm{m}^{2}$ while weight was $126 \pm 19 \mathrm{~kg}$ and $161 \pm 27 \mathrm{~kg}$, respectively. Subtherapeutic anti-Xa levels were observed in $21 \%$ of the patients who received a $40 \mathrm{mg}$ dose and $14 \%$ of patients who received a $60 \mathrm{mg}$ dose. There were no patients in the $40 \mathrm{mg}$ cohort who were supratherapeutic but $17 \%$ were supratherapeutic in the $60 \mathrm{mg}$ group. Bleeding was not associated with a high Xa-level. For a descriptive evaluation of these and other studies, the reader is referred to Additional file 1.

Summary: Critically ill obese patients who receive low molecular weight heparin require a higher dosage for VTE prophylaxis than patients who are not obese. Most data are with enoxaparin and the only dosing regimen associated with a reduction in VTE rate is $40 \mathrm{mg}$ twice daily. In patients with more extreme forms of obesity (i.e., $\mathrm{BMI} \geq 50 \mathrm{~kg} / \mathrm{m}^{2}$ ), higher doses may be necessary. There is wide disparity in the dosing regimens suggested for these patients including a BMI-stratified approach $(60 \mathrm{mg}$ twice daily, equivalent to approximately $0.4 \mathrm{mg} / \mathrm{kg} / \mathrm{dose}$ based on reported weights) to a weight-based approach ranging from $0.5 \mathrm{mg} / \mathrm{kg}$ once daily to $0.5 \mathrm{mg} / \mathrm{kg}$ twice daily. For patients with a BMI exceeding $40 \mathrm{~kg} / \mathrm{m}^{2}$, enoxaparin $40 \mathrm{mg}$ twice daily is appropriate. For patients with a $\mathrm{BMI} \geq 50 \mathrm{~kg} / \mathrm{m}^{2}$, a weight-based approach of $0.4-0.5 \mathrm{mg} /$ $\mathrm{kg}$ twice daily based on total body weight is suggested. Given the lack of consistency with dosing suggestions across pharmacokinetic studies, anti-Xa monitoring seems reasonable in this population.

Unfractionated heparin dosing has also been evaluated in obese hospitalized patients (Additional file 1) [70-72]. Patanwala, et al. compared VTE rates in obese $\left(\mathrm{BMI} \geq 30 \mathrm{~kg} / \mathrm{m}^{2}\right)$ and non-obese $\left(\mathrm{BMI}<30 \mathrm{~kg} / \mathrm{m}^{2}\right)$ populations who received heparin 5000 units three times daily [71]. There were 5110 patients assessed (approximately $26 \%$ were critically ill) and no difference in VTE rate was noted (obese, $0.7 \%$ vs. non-obese, $0.6 \% ; p=0.7$ ). Joy, et al. compared heparin doses of 7500 units with 5000 units every $8 \mathrm{~h}$ in patients who weighed more than $100 \mathrm{~kg}$ [70]. Approximately $37 \%$ were admitted to an ICU. Overall, there was no difference in VTE rate between the highdose and low-dose groups ( $3 \%$ vs. $1.5 \%, p=0.14$ ). Furthermore, in the patients with a BMI $\geq 40 \mathrm{~kg} / \mathrm{m}^{2}$, VTE rates were $3 \%$ (high-dose) and $2 \%$ (low-dose), $p=0.43$. Next, unfractionated heparin dosing was evaluated in a retrospective study of neurocritical care patients [72]. Patients who weighed over $100 \mathrm{~kg}$ were stratified based on receipt of a traditional (5000 units every $8 \mathrm{~h}$ ) or high (7500 units every $8 \mathrm{~h}$ ) heparin dose. There were 398 patients included with an average weight of $116 \mathrm{~kg}$ (traditional dose) and $123 \mathrm{~kg}$ (high dose). The incidence of VTE was $9.3 \%$ and $5.7 \%(p=0.2)$ for the traditional and high heparin doses, respectively. There was no difference in major bleeding events ( $11 \%$ vs. $14 \%, p=0.33)$. Finally, high-dose unfractionated heparin (7500 units every $8 \mathrm{~h}$ ) was compared to enoxaparin $40 \mathrm{mg}$ every $12 \mathrm{~h}$ in a retrospective study of obese hospitalized patients (mean $\mathrm{BMI}=49.5 \pm 8.9 \mathrm{~kg} / \mathrm{m}^{2}$ ) [73]. No difference in VTE rate was reported but major bleeding events were higher with unfractionated heparin [OR(95\% CI) 1.85 (1.07-3.13)].

Summary: Critically ill obese patients who receive unfractionated heparin for VTE prophylaxis appear to have equal benefit with traditional and high-dosing regimens. When unfractionated heparin is utilized in this population, 5000 units every $8 \mathrm{~h}$ is appropriate. In patients with more extreme forms of obesity $\left(\mathrm{BMI} \geq 50 \mathrm{~kg} / \mathrm{m}^{2}\right), 7500$ units every $8 \mathrm{~h}$ can be considered.

\section{Conclusion}

High-level evidence describing dosing of supportive care medications in obesity is lacking. Many of the medications used for supportive care can be dosed using a similar strategy to that observed in non-obese patients (e.g., vasopressors, corticosteroids and acid-suppressants). Anticoagulants for VTE prophylaxis, on the other hand, require an individualized approach. Therapeutic drug monitoring should be used where available. Further research is necessary to guide medication dosing in obese, critically ill patients.

\section{Supplementary Information}

The online version contains supplementary material available at https://doi. org/10.1186/s13054-021-03495-8.

Additional file 1: Pharmacokinetic and clinical trials involving low molecular weight heparin and unfractionated heparin.

\section{Abbreviations}

BMI: Body mass index; CIB: Clinically important bleeding; GERD: Gastroesophageal reflux disease; H2RA: Histamine 2 receptor antagonist; IBW: Ideal body weight; ICU: Intensive care unit; LBW: Lean body weight; PPI: Proton pump inhibitor; SUP: Stress ulcer prophylaxis; VTE: Venous thromboembolism. 


\section{Acknowledgements \\ Not applicable.}

\section{Authors' contributions}

BLE and JFB contributed to development of manuscript outline, literature search, literature evaluation, crafting of recommendations, manuscript preparation and critical review. Both authors read and approved the final manuscript.

\section{Funding}

None.

\section{Availability of data and materials}

Not applicable.

\section{Ethics approval and consent to participate}

Not applicable.

\section{Consent for publication}

Not applicable.

\section{Competing interests}

Brian L. Erstad declares that the he has no competing interests. Jeffrey F. Barletta: Consultant for Wolters Kluwer.

\section{Author details}

${ }^{1}$ Department of Pharmacy Practice and Science, College of Pharmacy, University of Arizona, 1295 N Martin Ave, PO Box 210202, Tucson, AZ 85721 , USA. ${ }^{2}$ Department of Pharmacy Practice, College of Pharmacy, Midwestern University, 19555 N 59th Ave, Glendale, AZ 85308, USA.

Received: 17 November 2020 Accepted: 8 February 2021

Published online: 23 February 2021

\section{References}

1. Hales CM, Carroll MD, Fryar CD, Ogden CL. Prevalence of obesity and severe obesity among adults: United States, 2017-2018. NCHS Data Brief. 2020:360:1-8

2. Eastman C, Erstad BL. Availability of information for dosing ocmmonly used medications in special ICU populations. Am J Health Syst Pharm. 2020;77(7):529-34.

3. Jacques KA, Erstad BL. Availability of information for dosing injectable medications in underweight or obese patients. Am J Health Syst Pharm. 2010:67(22):1948-50.

4. Pai MP, Paloucek FP. The origin of the "ideal" body weight equations. Ann Pharmacother. 2000;34(9):1066-9.

5. Janmahasatian S, Duffull SB, Ash S, Ward LC, Byrne NM, Green B. Quantification of lean bodyweight. Clin Pharmacokinet. 2005:44(10):1051-65.

6. Schetz M, De Jong A, Deane AM, Druml W, Hemelaar P, Pelosi P, et al. Obesity in the critically ill: a narrative review. Intensive Care Med. 2019:45(6):757-69.

7. Erstad BL. Designing drug regimens for special intensive care unit populations. World J Crit Care Med. 2015:4(2):139-51.

8. ASHP Therapeutic Guidelines on Stress Ulcer Prophylaxis. ASHP Commission on Therapeutics and approved by the ASHP Board of Directors on November 14, 1998. Am J Health Syst Pharm. 1999;56(4):347-79.

9. Annane D, Pastores SM, Rochwerg B, Arlt W, Balk RA, Beishuizen A, et al. Guidelines for the diagnosis and management of critical illness-related corticosteroid insufficiency (CIRCI) in critically ill patients (part I): Society of Critical Care Medicine (SCCM) and European Society of Intensive Care Medicine (ESICM) 2017. Crit Care Med. 2017;45(12):2078-88.

10. Kahn SR, Lim W, Dunn AS, Cushman M, Dentali F, Akl EA, et al. Prevention of VTE in nonsurgical patients: antithrombotic therapy and prevention of thrombosis, 9th ed: American College of Chest Physicians EvidenceBased Clinical Practice Guidelines. Chest. 2012;141(2 Suppl):e195S-e226S.

11. Pastores SM, Annane D, Rochwerg B. Guidelines for the diagnosis and management of critical illness-related corticosteroid insufficiency (CIRCI) in critically ill patients (part II): Society of Critical Care Medicine (SCCM) and European Society of Intensive Care Medicine (ESICM) 2017. Crit Care Med. 2018;46(1):146-8.

12. Rhodes A, Evans LE, Alhazzani W, Levy MM, Antonelli M, Ferrer R, et al. Surviving sepsis campaign: international guidelines for management of sepsis and septic shock: 2016. Crit Care Med. 2017;45(3):486-552.

13. Meng L, Mui E, Holubar MK, Deresinski SC. Comprehensive guidance for antibiotic dosing in obese adults. Pharmacotherapy. 2017;37(11):1415-31.

14. Pai MP, Bearden DT. Antimicrobial dosing considerations in obese adult patients. Pharmacotherapy. 2007:27(8):1081-91.

15. Polso AK, Lassiter JL, Nagel JL. Impact of hospital guideline for weightbased antimicrobial dosing in morbidly obese adults and comprehensive literature review. J Clin Pharm Ther. 2014;39(6):584-608.

16. Erstad BL, Barletta JF. Drug dosing in the critically ill obese patient-a focus on sedation, analgesia, and delirium. Crit Care. 2020;24(1):315.

17. Erstad BL, Barletta JF. Dosing of neuromuscular blocking agents in patients with obesity: a narrative review. Anaesth Intensive Care (in press).

18. Wishart DS, Feunang YD, Guo AC, Lo EJ, Marcu A, Grant JR, et al. DrugBank 5.0: a major update to the DrugBank database for 2018. Nucleic Acids Res. 2018;46(D1):D1074-82.

19. Giapreza (angiotensin II) [package insert]. San Diego, CA: LaJolla Pharmaceutical Company; 12/2017

20. Abboud I, Lerolle N, Urien S, Tadie JM, Leviel F, Fagon JY, et al. Pharmacokinetics of epinephrine in patients with septic shock: modelization and interaction with endogenous neurohormonal status. Crit Care. 2009;13(4):R120.

21. Beloeil H, Mazoit JX, Benhamou D, Duranteau J. Norepinephrine kinetics and dynamics in septic shock and trauma patients. Br J Anaesth. 2005;95(6):782-8.

22. Johnston AJ, Steiner LA, O'Connell M, Chatfield DA, Gupta AK, Menon DK. Pharmacokinetics and pharmacodynamics of dopamine and norepinephrine in critically ill head-injured patients. Intensive Care Med 2004:30(1):45-50.

23. Klem C, Dasta JF, Reilley TE, Flancbaum LJ. Variability in dobutamine pharmacokinetics in unstable critically ill surgical patients. Crit Care Med. 1994:22(12):1926-32

24. Adams C, Tucker C, Allen B, McRae A, Balazh J, Horst S, et al. Disparities in hemodynamic resuscitation of the obese critically ill septic shock patient. J Crit Care. 2017;37:219-23.

25. Arabi YM, Dara SI, Tamim HM, Rishu AH, Bouchama A, Khedr MK, et al. Clinical characteristics, sepsis interventions and outcomes in the obese patients with septic shock: an international multicenter cohort study. Crit Care. 2013;17(2):R72.

26. Wacharasint $P$, Boyd JH, Russell JA, Walley KR. One size does not fit all in severe infection: obesity alters outcome, susceptibility, treatment, and inflammatory response. Crit Care. 2013;17(3):R122.

27. Hodge EK, Hughes DW, Attridge RL. Effect of body weight on hemodynamic response in patients receiving fixed-dose vasopressin for septic shock. Ann Pharmacother. 2016:50(10):816-23.

28. Lam SW, Bauer SR, Cha SS, Oyen LJ. Lack of an effect of body mass on the hemodynamic response to arginine vasopressin during septic shock. Pharmacotherapy. 2008;28(5):591-9.

29. Miller JT, Welage LS, Kraft MD, Alaniz C. Does body weight impact the efficacy of vasopressin therapy in the management of septic shock? J Crit Care. 2012;27(3):289-93.

30. Radosevich JJ, Patanwala AE, Erstad BL. Norepinephrine dosing in obese and nonobese patients with septic shock. Am J Crit Care. 2016:25(1):27-32

31. Wong PJ, Pandya KA, Flannery AH. Evaluating the impact of obesity on safety and efficacy of weight-based norepinephrine dosing in septic shock: a single-center, retrospective study. Intensive Crit Care Nurs. 2017:41:104-8

32. Incollingo Rodriguez AC, Epel ES, White ML, Standen EC, Seckl JR, Tomiyama AJ. Hypothalamic-pituitary-adrenal axis dysregulation and cortisol activity in obesity: a systematic review. Psychoneuroendocrinology. 2015;62:301-18.

33. Dunn TE, Ludwig EA, Slaughter RL, Camara DS, Jusko WJ. Pharmacokinetics and pharmacodynamics of methylprednisolone in obesity. Clin Pharmacol Ther. 1991:49(5):536-49.

34. Milsap RL, Plaisance Kl, Jusko WJ. Prednisolone disposition in obese men. Clin Pharmacol Ther. 1984:36(6):824-31. 
35. Strehl C, Buttgereit F. Optimized glucocorticoid therapy: teaching old drugs new tricks. Mol Cell Endocrinol. 2013;380(1-2):32-40.

36. Venkatesh B, Cohen J, Cooper M. Ten false beliefs about cortisol in critically ill patients. Intensive Care Med. 2015;41 (10):1817-9.

37. Barletta JF, Kanji S, MacLaren R, Lat I, Erstad BL. Pharmacoepidemiology of stress ulcer prophylaxis in the United States and Canada. J Crit Care. 2014;29(6):955-60.

38. Alhazzani W, Guyatt G, Alshahrani M, Deane AM, Marshall JC, Hall R, et al. Withholding pantoprazole for stress ulcer prophylaxis in critically ill patients: a pilot randomized clinical trial and meta-analysis. Crit Care Med. 2017:45(7):1121-9.

39. Krag M, Marker S, Perner A, Wetterslev J, Wise MP, Schefold JC, et al. Pantoprazole in patients at risk for gastrointestinal bleeding in the ICU. N Engl J Med. 2018:379(23):2199-208.

40. Selvanderan SP, Summers MJ, Finnis ME, Plummer MP, Ali Abdelhamid Y, Anderson MB, et al. Pantoprazole or placebo for stress ulcer prophylaxis (POP-UP): randomized double-blind exploratory study. Crit Care Med. 2016:44(10):1842-50

41. Morrish GA, Pai MP, Green B. The effects of obesity on drug pharmacokinetics in humans. Expert Opin Drug Metab Toxicol. 2011;7(6):697-706.

42. Loomis AK, Kabadi S, Preiss D, Hyde C, Bonato V, St Louis M, et al. Body mass index and risk of nonalcoholic fatty liver disease: two electronic health record prospective studies. $J$ Clin Endocrinol Metab. 2016;101(3):945-52.

43. Lipsy RJ, Fennerty B, Fagan TC. Clinical review of histamine2 receptor antagonists. Arch Intern Med. 1990;150(4):745-51.

44. Bruley des Varannes S, Coudsy B, Waechter S, Delemos B, Xiang J, Lococo J, et al. On-demand proton pump inhibitory treatment in overweight/obese patients with gastroesophageal reflux disease: are there pharmacodynamic arguments for using higher doses? Digestion. 2013;88(1):56-63.

45. Pace F, Coudsy B, DeLemos B, Sun Y, Xiang J, LoCoco J, et al. Does BMI affect the clinical efficacy of proton pump inhibitor therapy in GERD? The case for rabeprazole. Eur J Gastroenterol Hepatol. 2011;23(10):845-51.

46. Shah SL, Lacy BE, DiBaise JK, Vela MF, Crowell MD. The impact of obesity on oesophageal acid exposure time on and off proton pump inhibitor therapy. Aliment Pharmacol Ther. 2015;42(9):1093-100.

47. Sharma P, Vakil N, Monyak JT, Silberg DG. Obesity does not affect treatment outcomes with proton pump inhibitors. J Clin Gastroenterol. 2013;47(8):672-7.

48. Shakhnovich V, Abdel-Rahman S, Friesen CA, Weigel J, Pearce RE, Gaedigk $A$, et al. Lean body weight dosing avoids excessive systemic exposure to proton pump inhibitors for children with obesity. Pediatr Obes. 2019;14(1):e12459.

49. Shakhnovich V, Smith PB, Guptill JT, James LP, Collier DN, Wu H, et al. Obese children require lower doses of pantoprazole than nonobese peers to achieve equal systemic drug exposures. J Pediatr. 2018;193(102-8):e1.

50. Abernethy DR, Greenblatt DJ, Matlis R, Gugler R. Cimetidine disposition in obesity. Am J Gastroenterol. 1984;79(2):91-4.

51. Bauer LA, Wareing-Tran C, Edwards WA, Raisys V, Ferreri L, Jack $R$, et al. Cimetidine clearance in the obese. Clin Pharmacol Ther. 1985:37(4):425-30.

52. Davis RL, Quenzer RW, Bozigian HP, Warner CW. Pharmacokinetics of ranitidine in morbidly obese women. Dicp. 1990;24(11):1040-3.

53. Mahajan V, Hashmi J, Singh R, Samra T, Aneja S. Comparative evaluation of gastric $\mathrm{pH}$ and volume in morbidly obese and lean patients undergoing elective surgery and effect of aspiration prophylaxis. J Clin Anesth. 2015;27(5):396-400

54. Lim W, Meade M, Lauzier F, Zarychanski R, Mehta S, Lamontagne F, et al. Failure of anticoagulant thromboprophylaxis: risk factors in medicalsurgical critically ill patients*. Crit Care Med. 2015;43(2):401-10.

55. Garcia DA, Baglin TP, Weitz Jl, Samama MM. Parenteral anticoagulants: antithrombotic therapy and prevention of thrombosis, 9th ed: American College of Chest Physicians Evidence-Based Clinical Practice Guidelines. Chest. 2012;141(2 Suppl):e24S-e43S.

56. Frederiksen SG, Hedenbro JL, Norgren L. Enoxaparin effect depends on body-weight and current doses may be inadequate in obese patients. $\mathrm{Br}$ J Surg. 2003;90(5):547-8.
57. Cook D, Crowther M, Meade M, Rabbat C, Griffith L, Schiff D, et al. Deep venous thrombosis in medical-surgical critically ill patients: prevalence, incidence, and risk factors. Crit Care Med. 2005;33(7):1565-71.

58. Roberts JA, Taccone FS, Lipman J. Understanding PK/PD. Intensive Care Med. 2016;42(11):1797-800.

59. Bickford A, Majercik S, Bledsoe J, Smith K, Johnston R, Dickerson J, et al. Weight-based enoxaparin dosing for venous thromboembolism prophylaxis in the obese trauma patient. Am J Surg. 2013;206(6):847-51.

60. Borkgren-Okonek MJ, Hart RW, Pantano JE, Rantis PC Jr, Guske PJ, Kane $\mathrm{JM} \mathrm{Jr}$, et al. Enoxaparin thromboprophylaxis in gastric bypass patients: extended duration, dose stratification, and antifactor Xa activity. Surg Obes Relat Dis. 2008;4(5):625-31.

61. Freeman A, Horner T, Pendleton RC, Rondina MT. Prospective comparison of three enoxaparin dosing regimens to achieve target anti-factor Xa levels in hospitalized, medically ill patients with extreme obesity. Am J Hematol. 2012;87(7):740-3.

62. Ludwig KP, Simons HJ, Mone M, Barton RG, Kimball EJ. Implementation of an enoxaparin protocol for venous thromboembolism prophylaxis in obese surgical intensive care unit patients. Ann Pharmacother. 2011:45(11):1356-62.

63. Miranda S, Le Cam-Duchez V, Benichou J, Donnadieu N, Barbay V, Le Besnerais M, et al. Adjusted value of thromboprophylaxis in hospitalized obese patients: a comparative study of two regimens of enoxaparin: the ITOHENOX study. Thromb Res. 2017;155:1-5.

64. Parikh S, Jakeman B, Walsh E, Townsend K, Burnett A. Adjusted-dose enoxaparin for VTE prevention in the morbidly obese. J Pharm Technol. 2015;31(6):282-8.

65. Rondina MT, Wheeler M, Rodgers GM, Draper L, Pendleton RC. Weightbased dosing of enoxaparin for VTE prophylaxis in morbidly obese, medically-IIl patients. Thromb Res. 2010;125(3):220-3.

66. Rowan BO, Kuhl DA, Lee MD, Tichansky DS, Madan AK. Anti-Xa levels in bariatric surgery patients receiving prophylactic enoxaparin. Obes Surg. 2008;18(2):162-6.

67. Scholten DJ, Hoedema RM, Scholten SE. A comparison of two different prophylactic dose regimens of low molecular weight heparin in bariatric surgery. Obes Surg. 2002;12(1):19-24.

68. Simone EP, Madan AK, Tichansky DS, Kuhl DA, Lee MD. Comparison of two low-molecular-weight heparin dosing regimens for patients undergoing laparoscopic bariatric surgery. Surg Endosc. 2008;22(11):2392-5.

69. Wang TF, Milligan PE, Wong CA, Deal EN, Thoelke MS, Gage BF. Efficacy and safety of high-dose thromboprophylaxis in morbidly obese inpatients. Thromb Haemost. 2014;111(1):88-93.

70. Joy M, Tharp E, Hartman H, Schepcoff S, Cortes J, Sieg A, et al. Safety and efficacy of high-dose unfractionated heparin for prevention of venous thromboembolism in overweight and obese patients. Pharmacotherapy. 2016;36(7):740-8.

71. Patanwala AE, Seaman SM, Kopp BJ, Erstad BL. Heparin dosing for venous thromboembolism prophylaxis in obese hospitalized patients: an observational study. Thromb Res. 2018;169:152-6.

72. Samuel S, lluonakhamhe EK, Adair E, Macdonald N, Lee K, Allison TA, et al. High dose subcutaneous unfractionated heparin for prevention of venous thromboembolism in overweight neurocritical care patients. J Thromb Thrombolysis. 2015:40(3):302-7.

73. Mason SW, Barber A, Jones E, Chen SL, Moll S, Northam K. Safety and efficacy of high-dose unfractionated heparin versus high-dose enoxaparin for venous thromboembolism prevention in morbidly obese hospitalized patients. Am J Med. 2020;133(6):e249-59.

74. Devine BJ. Case number 25: gentamicin therapy. Drug Intell Clin Pharm. $1974 ; 8: 650-5$.

75. Bauer LA, Edwards WA, Dellinger EP, Simonowitz DA. Influence of weight on aminoglycoside pharmacokinetics in normal weight and morbidly obese patients. Eur J Clin Pharmacol. 1983;24(5):643-7.

\section{Publisher's Note}

Springer Nature remains neutral with regard to jurisdictional claims in published maps and institutional affiliations. 